\title{
Water preloading before main meals as a strategy to treat adult patients with overweight or obesity
}

\section{Opinion}

The current obesity epidemic is a major public health concern worldwide, in both develop and developing countries. Obesity disease is associated with an increased risk for developing cardiovascular diseases, type 2 diabetes mellitus, osteoarthritis and some forms of cancer, weight loss associated with reductions in risk of morbidity and mortality.

Classically the treatment of obese people is based on lifestyle change, with 2 important components, dietary modification and increased physical activity. With this approach, significant weight losses are achieved, however, after more or less time, a weight regain occur. Evidence from systematic reviews suggests that longterm weight loss through changes in eating and physical activity is possible. ${ }^{2,3}$ In this context, there is need to investigate the effectiveness of simple, pragmatic interventions that could reach the many people needing lose weight, although such interventions result in modest reduction in body weight, since even small reductions across the whole population can have important public health benefits. ${ }^{4}$

One potential strategy to reduce meal energy intake is to modify the individual perception of fullness prior to eating by the use of preload of water. The effect of water overload on weight loss can not only be attributed to an early feeling of satiety but also increases the energy expenditure. Boshmann et al, ${ }^{5}$ observed that drinking $500 \mathrm{ml}$ of water increases metabolic rate by $30 \%$ in both women and men, they calculate that increasing water ingestion by 1.5 liters would increase daily energy expenditure by approximately $200 \mathrm{Kj}$. They estimated that over 1yr energy expenditure would increase by $73,000 \mathrm{Kj}$ $(17,400 \mathrm{Kcal})$, the energy content of $2.4 \mathrm{Kg}$ adipose tissue. The fact that the treatment with beta-adrenoreceptor blocker agents substantially attenuated the water-induced increase in metabolic rate suggested that increase in metabolic rate with water is related to sympathetic activation and increased stimulation of beta-adrenergic receptors. Another study by the same group of researchers ${ }^{6}{ }^{2}$ exclude volumerelated effects or gastric distension as the mediator of the thermogenic response to water drinking, they hypothesize the existence of a portal osmoreceptor, most likely an ion channel.

Information on the clinical application of water overload in the management of patients with overweight or obesity is scarce. Two studies compared patients drinking preload $500 \mathrm{ml}$ of water $30 \mathrm{~min}$ before a meal with those patients not drink a preload of water before a meal. The authors found that energy intake at the meal were lower for the preload group compared with non-preload group. ${ }^{7,8}$ Another study directly compared the effect of water preloading of $500 \mathrm{ml}$ of water before main meals in a group of overweight or obese patients (preload water group) over 12 weeks with another group of patients treated only with a hypocaloric diet (non-water group). The first group lost $2 \mathrm{~kg}$ more than the non-water group. The overall dietary energy density decreased significantly more in the water preload group. ${ }^{9}$ Recently Parreti et al ${ }^{10}$ observed evidence that water preloading before main meals leads to a moderate weight loss at follow up, the authors
Volume 8 Issue 3 - 2020

\author{
Ricardo V Garcia-Mayor \\ Department of Endocrinology \& Nutrition Unit, HM Hospital \\ of Vigo, Spain
}

\begin{abstract}
Correspondence: Ricardo V. Garcia-Mayor, Endocrinology \& Nutrition Unit, HM Hospital of Vigo, I I Manuel Olivie Street, 36203 Vigo, Spain, Email ricardo.garciamayor@sergas.es and
\end{abstract} rvgarciamayor@hmhopitales.com

Received: June 17, 2020 | Published: June 30, 2020

proposing this practice as a strategy for the treatment of overweight or obese people in primary care.

Overall, these data suggested that water overload is a simple and realistic method that could be useful as a treatment or adjuvant in treatment of adult patients with overweight or obesity in routine clinical practice.

\section{Acknowledgments}

None.

\section{Conflicts of interest}

No conflicts of interest, financial or otherwise, are declared by the author.

\section{References}

1. Aronne LJ, Isoldi KK. Overweight and obesity: key components of cardiometabolic risk. Clin Comerstone. 2007;8:29-37.

2. Poobalan AS, Aucott LS, Smith WC, et al. Long-term weight loss effects on all cause mortality in overweight/obese populations. Obes Rev. 2007;8:503-513.

3. Avenell A, Broom J, Brown TJ, et al. Systemic review of the longterm effects and economic consequences of treatments for obesity and implications for health improvement. Health Technol Assess. 2004;8(iiiiv): $1-182$.

4. Dombrowski SU, Knitte K, Avenell A, et al. Long-term maintenance of weight loss with non-surgical interventions in obese adults: systematic review and meta-analyses of randomised controlled trials. BMJ. 2014;348:2646.

5. Boschmann M, Steiniger J, Hille U, et al. Water-induced thermogenesis. J Clin Endocrinol Metab. 2003;88:6015-6019.

6. Boshmann M, Steiniger J, Franke G, et al. Water drinking induces thermogenesis through osmosensitive mechanisms. J Clin Endocrinol Metab. 2007;92:3334-3337. 
7. Van Walleghen EL, Orr JS, Gentile CL, et al. Pre-meal water consumption reduces meal energy intake in older but not younger subjects. Obesity. 2007;15:93-98.

8. Davy BM, Dennis EA, Dengo AL, et al. Water consumption reduces energy intake at a breakfast meal in obese older adults. $J$ Am Diet Assoc. 2008;108:1236-1239.
9. Dennis EA, Dengo AL, Comber DL, et al. Water consumption increases weight loss a simple method of coping with feeling of hunger, satiety and desire to eat. Obesity. 2010;18:300-307.

10. Parretti HM, Aveyard P, Blannin A, et al. Efficacy of water preloading before main meals as a strategy for weight loss in primary care patients with obesity: RCT. Obesity. 2015;23:1785-1791. 